\title{
Algumas Contribuições da Teoria da \\ Estrutura Retórica do Texto para o Ensino de Leitura e Compreensão de Textos na Escola
}

Contributions of Rhetorical Structure Theory to the Teaching of Reading and Text Comprehension in School

\author{
Juliano Desiderato ANTONIO *
}

Resumo: Este trabalho tem como objetivo argumentar a favor da importância de um trabalho em sala de aula que leve os alunos a refletir sobre as proposições implícitas que emergem tanto da combinação entre orações quanto da combinação entre porções maiores de um texto. Partindo dos pressupostos teóricos da RST, analisam-se dois textos tendo como escopo as relações retóricas cuja compreensão é indispensável para o estabelecimento da coerência do texto. $\mathrm{Na}$ sequência, propõem-se algumas atividades de reflexão sobre o texto que têm por objetivo levar o aluno ao reconhecimento das relações retóricas.

Palavras-chave: Estrutura retórica; RST; Coerência;

Abstract: The aim of this paper is to stress the importance of reading and text comprehension activities in school that focus on the recognition of implicit propositions which emerge both in clause combining and in the combining of text spams which are larger than clauses. Two texts are analysed based on the rhetorical relations that hold their coherence. Some activities are proposed for these texts in order to motivate students to reflect about and recognize these rhetorical relations. Key-words: Rhetorical structure; RST; Coherence.

* Doutor em Linguística e Língua Portuguesa pela UNESP-Araraquara (2004). Atualmente é docente da Universidade Estadual de Maringá. Contato: jdantonio@uem.br. 


\section{Introdução}

A leitura e a compreensão de textos escritos e de textos orais depende, dentre outros fatores, do reconhecimento de relações implícitas que são estabelecidas entre as partes do texto. Essas inferências, chamadas proposições relacionais (MANN \& THOMPSON, 1983), permeiam todo o texto, desde as porções maiores até as relações estabelecidas entre duas orações e ajudam a dar coerência ao texto, conferindo unidade e permitindo que o produtor atinja seus propósitos com o texto que produziu.

Um tratamento adequado a essa questão das proposições relacionais é oferecido pela RST (Rhetorical Structure Theory - Teoria da Estrutura Retórica do Texto), uma teoria descritiva que tem por objeto o estudo da organização dos textos, caracterizando as relações que se estabelecem entre as partes do texto (MANN \& THOMPSON, 1988; MATTHIESSEN \& THOMPSON, 1988; MANN, MAT'THIESSEN \& THOMPSON, 1992). A RST parte do princípio de que as relações retóricas que se estabelecem no nível discursivo organizam desde a coerência dos textos até a combinação entre orações (MATTHIESSEN \& THOMPSON, 1988).

Ao tratar das relações retóricas tanto no nível discursivo quanto no nível gramatical (combinação entre orações), a RST demonstra sua filiação à Linguística Funcional, um grupo de teorias que consideram essencial para o estudo da língua a função dos elementos linguísticos na comunicação (BUTLER, 2003; NEVES, 1997; NICHOLS, 1984). Mais especificamente, a RST foi desenvolvida no âmbito de outras duas teorias funcionalistas: a Gramática Sistêmico-Funcional de Halliday e o Funcionalismo da Costa-Oeste dos Estados Unidos (ANTONIO, 2009).

$\mathrm{Na}$ visão funcionalista, a comunicação não se dá por meio de frases, mas sim por meio do "discurso multiproposicional, organizado em estruturas que reconhecemos como caracterizando conversações, palestras, encontros de comitês, cartas formais e informais dentre outras" (BUTLER, 2003, p. 28, tradução nossa). Além disso, os chamados componentes 'gramaticais' da língua (regras fonológicas, morfológicas, sintáticas e semânticas) são considerados instrumentais em relação às regras de uso das expressões linguísticas (DIK, 1989), uma vez que o 
correlato psicológico de uma teoria funcionalista é a competência comunicativa do falante (DIK, 1989), termo utilizado por Hymes (1987) para se referir à capacidade que o falante tem não apenas de produzir enunciados gramaticalmente corretos, mas também adequados à situação comunicativa.

Neste artigo, pretende-se argumentar a favor de um trabalho escolar com a gramática que leve o aluno a refletir sobre as relações que se estabelecem entre partes do texto e entre orações. Inicialmente, serão apresentados alguns pressupostos básicos do Funcionalismo e da RST. Na sequência, serão apresentadas propostas de análise de textos a partir da metodologia da RST com atividades passíveis de serem desenvolvidas em sala de aula.

\section{Pressuspostos básicos do Funcionalismo}

Na visão funcionalista, o objetivo do estudo da gramática é explicar as funções dos meios linguísticos de expressão, ou seja, explicar como os falantes usam a língua para se comunicar com êxito (IVIR, 1987). A Gramática Sistêmico-Funcional de Halliday (1985), por exemplo, relaciona as metafunções da linguagem ("diferentes modos de sentido construídos pela gramática” - MATTHIESSEN \& HALLIDAY, 1997, p. 10) a sistemas gramaticais pelos quais essas metafunções são realizadas linguisticamente. As metafunções apresentadas por Halliday são a ideacional e a interpessoal, que estão relacionadas a fenômenos externos à língua, e a textual, que é intrínseca à língua.

A metafunção ideacional diz respeito aos recursos gramaticais utilizados para construir tanto as experiências interiores do falante quanto as experiências com o mundo ao seu redor. O sistema de transitividade é um dos principais recursos linguísticos utilizados para a realização dessa metafunção. Cada "experiência" do falante é construída a partir de uma configuração que consiste de um processo (verbo), dos participantes desse processo (argumentos) e das circunstâncias relativas ao processo.

A metafunção interpessoal está relacionada aos recursos gramaticais utilizados pelo falante para interagir com seus interlocutores, assumindo papéis sociais e papéis que dizem respeito à situação 
comunicativa. O sistema de modo é uma das principais formas de realização dessa metafunção, disponibilizando ao falante estratégias semânticas tais como adulação, persuasão, sedução, pedido, requisição, sugestão, afirmação, insistência, dúvida etc.

Por fim, a metafunção textual trata da apresentação do conteúdo interpessoal e ideacional na forma de informações que podem ser compartilhadas pelo falante e por seus interlocutores em textos adequados à situação de uso. Por meio da função ideacional, pode-se criar um referente mental dos argumentos que podem participar de um determinado processo, pode-se ter idéia dos papéis assumidos pelo falante e por seus interlocutores (quem dá ordens, quem recebe conselhos, quem faz pedidos, quem autoriza etc), mas é a função textual que instrumentaliza a apresentação desses conteúdos por meio de estratégias que permitem ao falante guiar seu(s) interlocutor(es) na interpretação do texto.

Assim, pode-se observar a relevância da gramática para a construção dos sentidos do texto. Para Halliday (1985), uma análise textual que não leva em conta a gramática com a qual esse texto foi construído representa simples comentários sobre o texto. Embora o texto seja uma unidade semântica, os sentidos são realizados por meio de expressões linguísticas, o que torna relevante a inclusão da análise dos elementos gramaticais na análise de um texto. Ainda segundo o linguista britânico (1985), a análise linguística tem duas finalidades no nível textual: (i) permite que se explique como e por que o texto diz o que diz; (ii) permite que se explique por que um texto produz ou não os resultados pretendidos por seu produtor, uma vez que leva em conta como as expressões linguísticas de um texto se relacionam com seu contexto, incluindo as intenções de quem está envolvido na produção do texto.

A relação entre discurso e gramática também está presente nos trabalhos dos pesquisadores que compõem o grupo funcionalista da Costa-Oeste. Um bom exemplo que caracteriza essa preocupação é a pesquisa de Hopper \& Thompson (1980) a respeito da transitividade na gramática e no discurso. Ao contrário da visão tradicional, que considera a transitividade uma propriedade categórica do verbo, para esses autores a transitividade é uma noção escalar, contínua, baseada em 10 parâmetros que permitem verificar a eficiência e a intensidade 
com que uma ação é transferida de um participante para outro. Assim, uma oração não é transitiva ou intransitiva, mas, dependendo no número de parâmetros de alta ou baixa transitividade, uma oração tem transitividade mais alta do que outra oração. Em sua pesquisa, Hopper \& Thompson (1980) verificaram que a transitividade exerce função discursiva. Orações com transitividade alta geralmente compõem a estrutura básica do texto, chamada figura. Por outro lado, orações com transitividade baixa compõem o fundo, partes do texto que trazem informações que subsidiam a compreensão da figura.

As observações a respeito da Gramática Sistêmico-Funcional de Halliday e as considerações a respeito da análise da transitividade na perspectiva do Funcionalismo da Costa-Oeste vão ao encontro da posição de Votre e Naro (1989), que propõem uma análise linguística no discurso, e não do discurso.

\section{A Teoria da Estrutura Retórica do Texto (RST)}

Como já foi dito anteriormente, a RST tem por objeto de estudo a organização dos textos, descrevendo as relações que se estabelecem entre as partes do texto. O pressuposto básico da RST é que, além do conteúdo proposicional explícito veiculado pelas orações de um texto, há proposições implícitas, as chamadas proposições relacionais, que surgem das relações que se estabelecem entre porções do texto.

Para Mann e Thompson (1983), o fenômeno das proposições relacionais é combinacional, definido no âmbito textual, ou seja, as proposições relacionais são resultantes da combinação de partes do texto. Essas combinações podem ser estabelecidas tanto entre orações, como entre porções maiores de texto. Uma outra observação importante diz respeito à natureza das relações. Quando duas porções de texto se relacionam, além do conteúdo proposicional expresso por cada uma das porções há também um conteúdo implícito, a proposição relacional.

Os pressupostos teóricos nos quais a RST se baseia são os seguintes:

a) os textos são formados por grupos organizados de orações que se relacionam hierarquicamente entre si de várias formas; 
b) as relações que se estabelecem entre as orações podem ser descritas com base na intenção comunicativa do enunciador e na avaliação que o enunciador faz do enunciatário, e refletem as escolhas do enunciador para organizar e apresentar os conceitos.

Uma lista de aproximadamente vinte e cinco relações foi estabelecida por Mann e Thompson (1987a) após a análise de centenas de textos, por meio da RST. Essa lista não representa um rol fechado, mas um grupo de relações suficiente para descrever a maioria dos textos. ${ }^{1}$

No que diz respeito à organização, as relações podem ser de dois tipos:

a) núcleo-satélite, nas quais uma porção do texto (satélite) é ancilar da outra (núcleo), como na figura 1 a seguir, em que um arco vai da porção que serve de subsídio para a porção que funciona como núcleo.

b) multinucleares, nas quais uma porção do texto não é ancilar da outra, sendo cada porção um núcleo distinto, como na figura 2 a seguir.

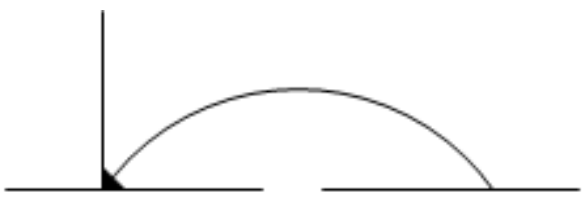

Figura 1-Esquema de relação núcleo-satélite

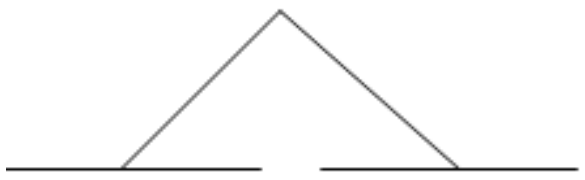

Figura 2-Esquema de relação multinuclear

${ }^{1}$ Uma lista com as relações e suas definições pode ser encontrada no site http:/ /www.sfu.ca/rst/07portuguese/definitions.html. 
No diagrama 1, observa-se um exemplo da formalização de uma análise textual por meio da RST. Nesse exemplo, ${ }^{2}$ observa-se que as relações se estabelecem tanto entre orações quanto entre porções de texto maiores do que a oração. Inicialmente, observa-se que a porção textual formada pelas unidades de 5 a 6 é um satélite que justifica o ato de fala composto pelas unidades de 1 a 4 . No interior dessa porção textual, estabelece-se uma relação multinuclear de contraste entre as porções formadas pelas unidades 1 e 2 e pelas unidades 3 e 4 . Entre as unidades 1 e 2, por sua vez, estabelece-se uma relação de causa entre o núcleo (unidade 1: oração nuclear) e o satélite (unidade 2: oração causal). No caso das orações 3 e 4, estabelece-se uma relação de condição entre o núcleo (unidade 4: oração nuclear) e o satélite (unidade 3: oração condicional). Por fim, entre as unidades 5 e 6 , estabelece-se uma relação de causa entre o núcleo (unidade 6: oração nuclear) e o satélite (unidade 5: oração causal).

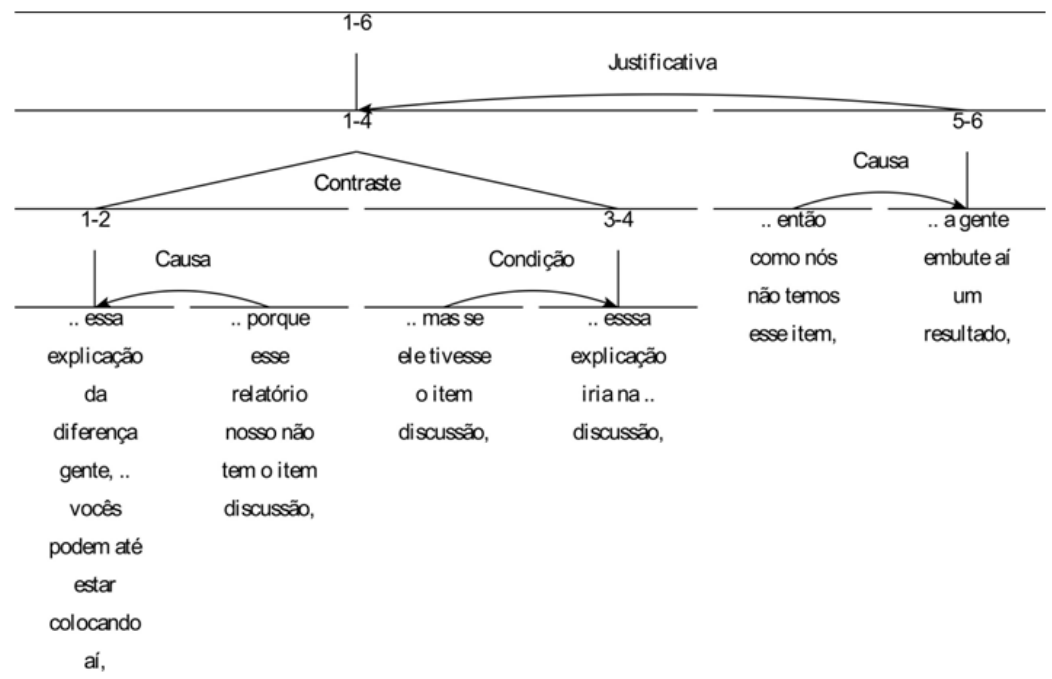

Diagrama 1 - Exemplo de formalização de análise textual por meio da RST

${ }^{2} \mathrm{O}$ exemplo do diagrama 1 foi retirado de uma elocução formal do tipo aula pertencente ao corpus do Funcpar (Grupo de Pesquisas Funcionalistas do Norte/ Noroeste do Paraná). 
É importante observar que, na visão da RST, as proposições relacionais surgem no texto independentemente de sinais específicos de sua existência: não há necessidade de inclusão, no texto, de elementos linguísticos que tenham por função indicar as relações estabelecidas (MANN \& THOMPSON, 1983). Pesquisas têm sido realizadas no sentido de identificar os meios linguísticos utilizados pelos falantes para marcar as relações retóricas (proposições relacionais). Alguns meios já descritos são marcadores discursivos, tempo e aspecto verbais, combinação entre orações (paratáticas/ hipotáticas). Outras pesquisas têm demonstrado também que as proposições relacionais podem ser reconhecidas pelo destinatário do texto sem ser necessariamente expressas por alguma marca formal (TABOADA, 2006).

É o que ocorre no exemplo do diagrama 2 a seguir, ${ }^{3}$ em que se pode observar a relação de causa entre as duas orações mesmo sem a presença de um conectivo como porque, pois, uma vez que etc.

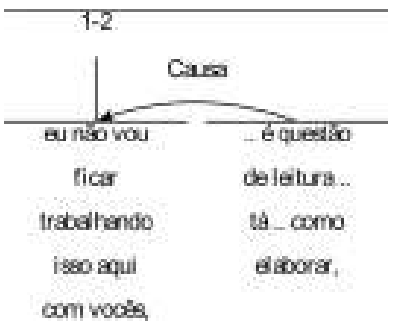

Diagrama 2 - Relação de causa não marcada por conectivo

Tradicionalmente, a classificação de orações adverbiais é feita com base na conjunção que inicia a oração. No entanto, como afirma Decat (2001, p. 120), “o que importa é a relação que existe entre as cláusulas”. De acordo com a proposta da RST, como, obviamente, o analista não tem acesso à mente do produtor do texto, a análise é feita com base em julgamentos de plausibilidade, ou seja, o analista julga que tais relações são plausíveis com base em seu conhecimento a respeito

\footnotetext{
${ }^{3} \mathrm{O}$ exemplo do diagrama 2 foi retirado de uma elocução formal do tipo aula pertencente ao corpus do Funcpar.
} 
do produtor do texto, dos seus prováveis destinatários, das convenções culturais e do contexto de produção do texto (MANN \& THOMPSON, 1988).

Nos exemplos dos diagramas 3 e 4 a seguir, ${ }^{4}$ por exemplo, o conectivo " $e$ " não é utilizado para introduzir orações aditivas, sua função considerada canônica. No caso do diagrama 3, a oração iniciada pelo "e" estabelece relação de propósito com a oração núcleo. A paráfrase plausível é que o sujeito será ensinado a emitir a resposta de pressão à barra para receber uma gota de água. No caso do diagrama 4, a conjunção $e$ marca relação de contraste entre a unidade 1 e as porções de texto $2 \mathrm{e}$ 3. A paráfrase plausível é de ideias contrárias: o rapaz tenta falar com a moça, mas é impedido pelo pai dela.

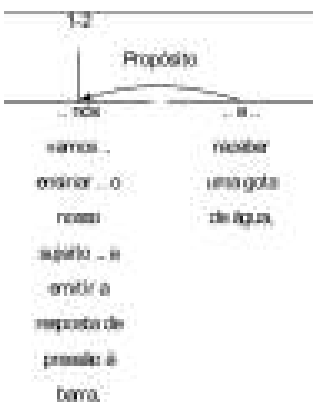

Diagrama 3 - Relação de propósito marcada pelo conectivo "e"

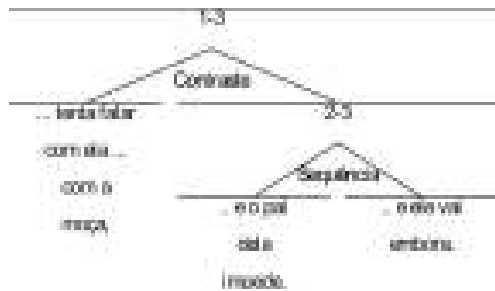

Diagrama 4 - Relação de contraste marcada pelo conectivo "e"

${ }^{4} \mathrm{O}$ exemplo do diagrama 3 foi retirado de uma elocução formal do tipo aula pertencente ao corpus do Funcpar. O exemplo do diagrama 4 foi retirado de uma narrativa oral pertencente ao corpus do Funcpar. 


\section{Analisando textos com a RST}

A estrutura retórica de um texto, representada por um diagrama arbóreo, é definida pelas redes de relações que se estabelecem entre porções de texto sucessivamente maiores. Segundo Mann e Thompson (1987a, 1987b), a estrutura retórica é funcional, pois leva em conta como o texto produz um efeito sobre o enunciatário, ou seja, toma como base as funções que as porções do texto assumem para que o texto atinja o objetivo global para o qual foi produzido.

Serão apresentadas, a seguir, propostas para análises de 2 textos a partir do modelo teórico-metodológico da RST.

No exemplo do diagrama 5, que representa a análise da estrutura retórica do texto publicitário "Felicidade não tem preço", 5 publicado na página 17 da revista Manequim, em abril de 2003, pode-se observar que o objetivo do produtor do texto é levar seu interlocutor a realizar as ações apresentadas nas unidades 3, 4, 5 e 6. A realização dessas ações, que deve ser efetuada na sequência apresentada, torna o interlocutor competente para concorrer aos prêmios apresentados nas unidades de 8 a 11. Assim, tem-se a "receita da felicidade", mencionada na unidade 2 , ou seja, as unidades de 3 a 6 acrescentam maiores detalhes ao conteúdo da unidade 2 , estabelecendo-se aí uma relação de elaboração. O conteúdo da unidade 2, por sua vez, é comparado com o conteúdo da unidade 1, mas levando-se em conta as diferenças existentes entre eles, motivo pelo qual se estabelece a relação de contraste.

\footnotetext{
${ }^{5} \mathrm{~A}$ análise desse texto pode ser encontrada em Antonio (2003).
} 


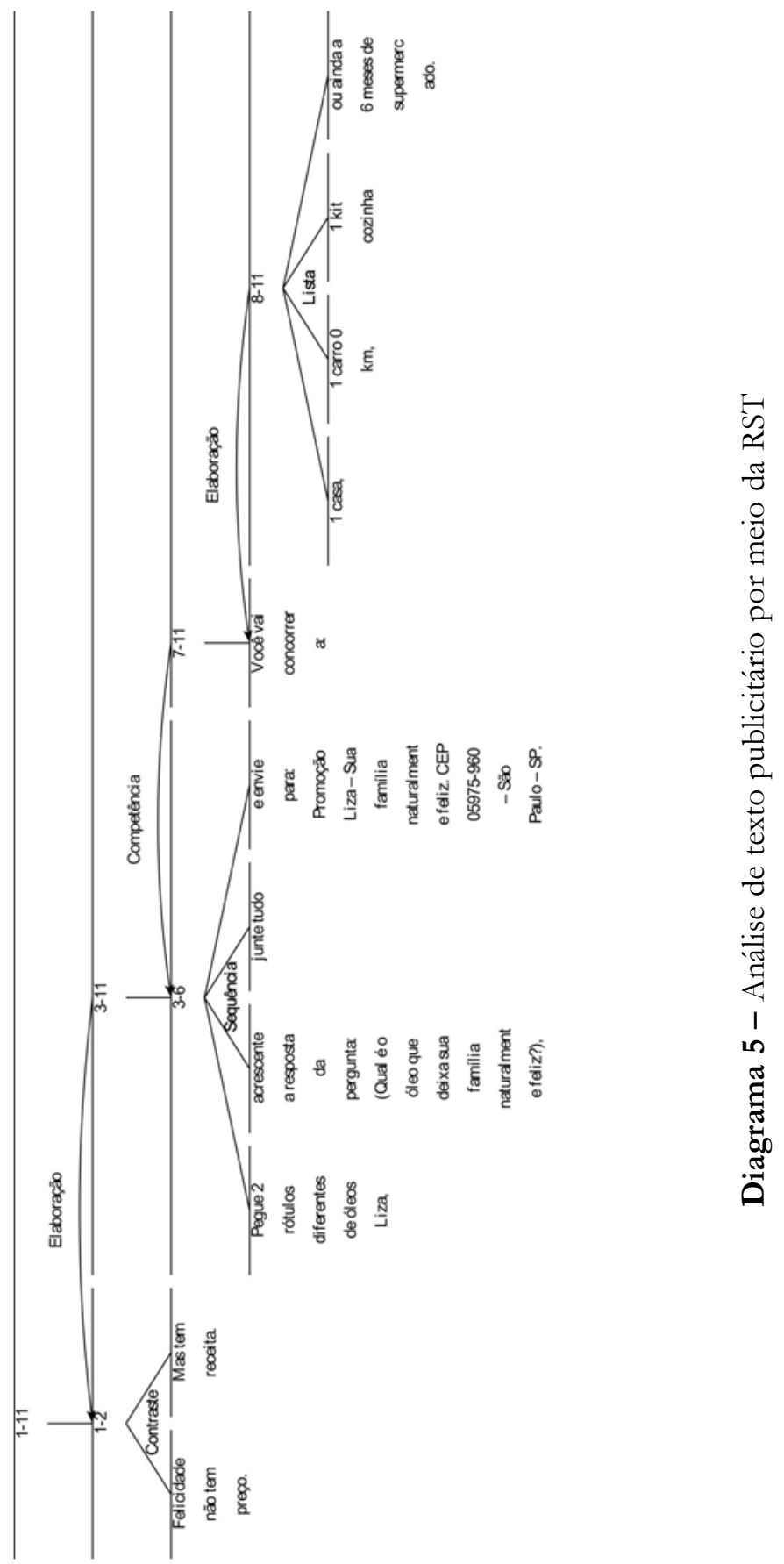

SIGNum: Estud. Ling., Londrina, n. 13/2, p. 81-100, dez. 2010 
No diagrama 6, apresenta-se a análise da estrutura retórica de um trecho de uma elocução formal. ${ }^{6}$ No trecho analisado, a relação de preparação que emerge nas unidades 1, 4 e 9 tem como objetivo tornar o interlocutor mais interessado no conteúdo do núcleo. As unidades 2 e 3 e as unidades 8 e 9 estabelecem relação de fundo, aumentando a capacidade do interlocutor de compreender o conteúdo do núcleo. Das porções de texto formadas pelas unidades de 2 a 7 e de 8 a 13 emerge a relação de lista, que liga elementos comparáveis.

${ }^{6} \mathrm{O}$ exemplo do diagrama 6 foi retirado de uma elocução formal do tipo aula do corpus do Funcpar. 


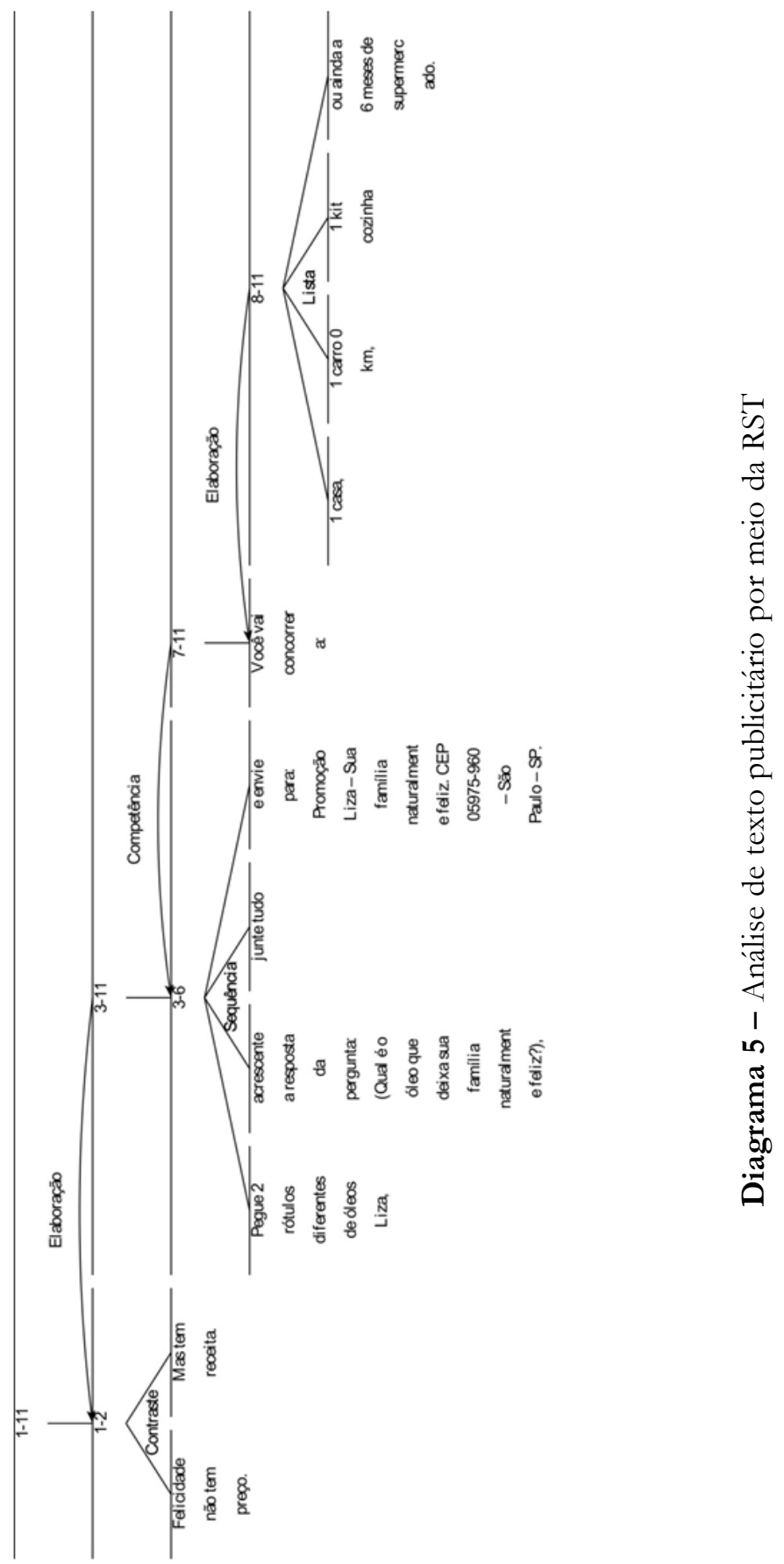

SIGNum: Estud. Ling., Londrina, n. 13/2, p. 81-100, dez. 2010 


\section{As proposições relacionais e o ensino de Língua Portuguesa}

Não se defende, neste artigo, que a teoria RST seja ensinada na escola. No entanto, a difusão dos princípios da RST entre os professores de Língua Portuguesa pode certamente trazer benefícios ao ensino.

O reconhecimento das proposições relacionais que emergem da combinação entre orações e entre porções de texto maiores do que a oração é fundamental para o estabelecimento da coerência dos textos. Se os professores partirem desse princípio, poderão deixar de lado a classificação meramente formal das orações adverbiais a partir dos conectivos.

Os professores podem, a partir de textos como os apresentados a título de exemplo nos diagramas 5 e 6 , elaborar atividades que levem os alunos a refletir sobre as relações que se estabelecem entre as partes do texto. Assim, partindo de atividades de gramática reflexiva, nas quais o conhecimento é construído a partir das reflexões do aluno (TRAVAGLIA, 1996), os professores podem mediar o processo de reconhecimento das proposições relacionais dos textos pelos alunos. A título de exemplo, apresentam-se, a seguir, algumas propostas de atividades que podem ser realizadas com os textos dos diagramas 5 e 6.

1 Felicidade não tem preço.

2 Mas tem receita.

3 Pegue 2 rótulos diferentes de óleos Liza,

4 acrescente a resposta da pergunta: (Qual é o óleo que deixa sua família naturalmente feliz?),

5 junte tudo

6 e envie para: Promoção Liza - Sua família naturalmente feliz. CEP 05975-960 - SP - SP.

7 Você vai concorrer a: 1 casa, 1 carro 0 km, 1 kit cozinha ou ainda a 6 meses de supermercado.

1- Releia as orações das linhas 1 e 2 do texto.

a) Qual dessas orações apresenta uma ideia na forma de uma afirmação? 
b) Qual dessas orações faz uma afirmação a partir de uma ideia contrária a uma outra afirmação?

c) Que conectivo é utilizado para indicar que as ideias dessas duas orações estão em contraste?

2- Releia os enunciados das linhas 3 a 6 do texto.

Agora, observe o trecho a seguir de uma receita culinária:

\section{Bolo de mel}

Junte 1 xícara de chá de mel, 1 xícara de chá de leite, 2 colheres de sopa de manteiga derretida.

Misture bem.

Acrescente 3 xícaras de chá de farinha, 1 xícara de chá de açúcar, 1 colher de chá de canela em pó, 1 colher de sobremesa de bicarbonato de sódio em $1 / 2$ xícara de água morna.

Bata à mão.

Asse por 30 minutos.

a) Que semelhanças há entre as formas verbais da receita culinária e as formas verbais dos enunciados das linhas 3 a 6 do texto?

b) Pode-se afirmar que os enunciados das linhas 3 a 6 do texto também constituem uma receita? Se sua resposta for afirmativa, os enunciados das linhas 3 a 6 do texto podem ser considerados uma receita de quê?

3- Observe o enunciado da linha 7 do texto. Não há um conectivo ligando esse enunciado aos enunciados anteriores. Mesmo assim, é possível saber que esse enunciado apresenta uma sanção positiva para os leitores que executarem algumas ações. Quais são elas?

Apresentam-se, a seguir, algumas propostas de atividades para o trecho da elocução formal analisado no diagrama 6 .

1 .. o homem o que que ele foi fazendo?

2 .. o sal .. ele tava lá no mar, .. bem quietinho, 
3 .. todo todo sal que a humanidade ingeria era proveniente do dos alimentos, .. dos vegetais, .. da própria carne.

4 .. com o passar do tempo o que que o homem fez?

5 .. foi lá no mar,

6 .. concentrou sal,

7 .. e jogou no alimento.

8 .. o homem só se alimentava de óleo presente nas castanhas, .. na própria carne, .. no no leite.

9 .. o que que o homem fez?

10 .. pegou a soja,

11 .. foi lá na indústria,

12 .. concentrou,

13 .. agora joga esse óleo na comida.

1 - No trecho da aula que estamos estudando, o professor fala sobre dois alimentos. Quais são eles? Quais linhas do texto tratam de cada um desses alimentos?

2- Observe que há 3 perguntas no texto: nas linhas 1, 4 e 9. Se o professor não espera uma resposta dos alunos, por que, então, ele faz as perguntas?

3- Leia novamente os enunciados das linhas 5, 6 e 7. A ordem em que as ações são expressas nesses enunciados pode ser alterada? E os enunciados das linhas 10-12? A ordem em que essas ações são expressas pode ser alterada?

4- Agora, vamos tentar transformar esse trecho de aula em um texto escrito.

a) Que palavras e expressões são informais e/ ou comuns na língua falada? Reescreva o texto substituindo essas palavras e expressões por expressões mais formais ou típicas da língua escrita.

b) Quantos parágrafos esse texto teria? Lembre-se de que as orações que compõem um parágrafo devem tratar de um mesmo assunto. Você acha que daria certo se as informações a respeito de cada um dos alimentos mencionados no texto 
formassem um parágrafo cada? Reescreva o texto, agrupando as orações em parágrafos. Procure adequar a pontuação às normas do português escrito.

c) Nos enunciados das linhas 5-7 e 10-12, observamos que há sequências de ações. Para indicar que essas ações estão em uma sequência, dispomos de alguns recursos na língua, como os elementos depois, depois disso, depois de, na sequência, em um momento posterior, em um momento seguinte etc. Reescreva o texto utilizando alguns desses elementos para indicar a sequência das ações nos enunciados mencionados.

d) Que título você daria ao texto? Lembre-se de que o título deve espelhar o conteúdo do texto e também deve despertar o interesse do leitor.

e) Você faria mais alterações no texto? Quais?

No texto a respeito do sal e do óleo, além das atividades que tinham por objetivo levar o aluno ao reconhecimento das relações retóricas, foram propostas também atividades de retextualização, entendidas por Marcuschi (2001) como atividades de transformação de um texto oral em um texto escrito. Como se pode observar, ao se trabalhar com a língua em uso, surgem muitas questões referentes à construção do texto (a organização em parágrafos, por exemplo), questões referentes a aspectos formais (emprego de conectivos para indicar a sequenciação das ações) e questões referentes a aspectos normativos (pontuação, adequação do vocabulário e das construções à modalidade escrita da língua).

É interessante que o professor solicite que os alunos tragam gramáticas e livros que ensinam produção textual, por exemplo, para que os alunos possam investigar por conta própria regras de pontuação, recursos linguísticos para expressar relações como a de sequenciação, etc. Dessa forma, estimula-se o aluno a refletir e a buscar informações. O professor deixa de ser o detentor do conhecimento para ser um mediador na interação entre o aluno, o texto e a gramática.

\section{Conclusão}

Neste trabalho, argumentou-se a favor da importância de um trabalho em sala de aula que leve os alunos a refletir sobre as proposições 
implícitas que emergem tanto da combinação entre orações quanto da combinação entre porções maiores de um texto. Partindo dos pressupostos teóricos da RST, dois textos foram analisados tendo como escopo as relações retóricas, cuja compreensão é indispensável para o estabelecimento da coerência do texto. $\mathrm{Na}$ sequência, foram propostas algumas atividades de reflexão sobre o texto que têm por objetivo levar o aluno ao reconhecimento das relações retóricas.

Embora a formalização das análises RST em diagramas arbóreos possa parecer complexa, é importante que os princípios da teoria sejam assimilados pelos professores, para que o trabalho em sala de aula deixe de ser meramente classificatório e formal e passe a valorizar o reconhecimento das proposições implícitas que ajudam a garantir a coerência do texto.

Por fim, espera-se que atividades como as que se propõem aqui possam ajudar na tão propagada mas difícil tarefa de integrar o ensino de gramática com o ensino de leitura e de produção de textos.

\section{Referências}

ANTONIO, J.D. Estrutura Retórica do Texto: uma proposta para a análise da coerência. Signótica, v. 15, n. 2, p. 223-236, 2003.

O texto como objeto de estudo na Linguística Funcional. In: . \& NAVARRO, P. O texto como objeto de ensino, de descrição lingüística e de análise textual e discursiva. Maringá: Eduem, 2009. p. 61-80.

BUTLER, C.S. Structure and function: a guide to three major structuralfunctional theories. Part 1: approaches to the simple clause. Amsterdam/ Philadelphia: J. Benjamins, 2003.

DECAT, M. B. A articulação hipotática adverbial no português em uso. In: . et al. (orgs.) Aspectos da gramática do português: uma abordagem funcionalista. Campinas: Mercado de Letras, 2001.

DIK, C. S. The Theory of Functional Grammar. Dordrecht: Foris, 1989. 
HALLIDAY, M. A. K. An introduction to functional grammar. Baltimore: Edward Arnold, 1985.

HYMES, D. On Communicative Competence. Sociolinguistics, v. 1, p. 219-229, 1987.

HOPPER, P.; THOMPSON, S. Transitivity in grammar and discourse. Language, v.56, n.2, p.252-299, 1980.

IVIR, V. Functionalism in Contrastive Analysis and Translation Studies. In: DIRVEN, R.; FRIED, V. (eds.) Functionalism in Linguistics. Amsterdam/Philadelphia: J. Benjamins, 1987. p. 471-481.

MANN, W. C.; THOMPSON, S. A. Relational propositions in Discourse. ISI/RR-83-115, 1983.

. Assertions from Discourse Structure. ISI/RS-85-155, 1985.

Rhetorical Structure Theory: a framework for the analysis of texts. ISI/RS-87-185, 1987a.

Rhetorical Structure Theory: a theory of text organization. ISI/ RS-87-190, $1987 \mathrm{~b}$.

. Rhetorical Structure Theory: Toward a functional theory of text organization. Text, v. 8, n. 3, p. 243-281, 1988.

MANN, W. C.; MATTTHIESSEN, C. M. I. M.; THOMPSON, S. A. Rhetorical Structure Theory and text analysis. In: MANN, W. C.; THOMPSON, S. A. (eds.) Discourse description: diverse linguistic analyses of a fund-raising text. Amsterdam/Philadelphia: J. Benjamins, 1992. p. $39-77$.

MARCUSCHI, L.A. Da fala para a escrita: atividades de retextualização. São Paulo: Cortez, 2001.

MATTHIESSEN, C.; THOMPSON, S. The structure of discourse and 'subordination'. In: HAIMAN, J.; THOMPSON, S. (eds.) Clause 
Combining in Grammar and Discourse. Amsterdam/Philadelphia: J. Benjamins, 1988. p. 275-329.

MATTHIESSEN, C.; HALLIDAY, M.A.K. Systemic functional grammar: a first step into the theory. 1997. Disponível em: <http:// minerva.ling.mq.edu.au/resource/VirtuallLibrary/Publications/ sfg_firststep/SFG intro New.html>. Acesso em <05/02/2009>.

NEVES, M.H.M.N. A Gramática Funcional. S. Paulo: Martins Fontes, 1997.

NICHOLS, J. Functional theories of grammar. Annual review of Anthropology, v. 43, 1984, p. 97-117.

TABOADA, M.; MANN, W.C. Rhetorical Structure Theory: Looking Back and Moving Ahead. Discourse Studies 8(3): 423-459, 2006.

TRAVAGLIA, Luiz Carlos . Gramática e interação: uma proposta para o ensino de gramática no primeiro e segundo graus. S. Paulo: Cortez, 1996.

VOTRE, S. J.; NARO, A. J. Mecanismos funcionais no uso da língua. D.E.L.T.A., v. 5, n. 2, p. 169-184, 1989. 